\title{
Informal Workplace Learning in Swedish Police Education- A Teacher Perspective
}

\author{
David Sjöberg $^{1}$ (1) Robert Holmgren ${ }^{2}$
}

Received: 30 January 2020 / Accepted: 15 February 2021/ Published online: 6 March 2021

(C) The Author(s) 2021

\begin{abstract}
In the literature, informal learning is considered to be of great importance to employees' development of workplace learning. The aim of this study, which involves respondents from a Swedish police education unit, was to contribute knowledge about Swedish police education teachers' informal learning as regards conditions for learning, learning activities and learning experiences resulting from their engagement in these activities. The results of the study are based on daily digital logbook notes made by 25 police and university teachers during one month and subsequent interviews with these teachers. The main conclusions can be summarised as follows: 1) The culture, structure and materials of the workplace are important parts of teachers' conditions for informal learning. 2) The teachers' informal learning activities are characterised by intentional learning, where supporting interactions with colleagues in their own teams and other, more knowledgeable, colleagues are highly valued. Furthermore, the most common triggers for teachers' informal learning are issues relating to pedagogy and digital technology, and face-to-face contacts with colleagues are preferred. 3) The police teachers describe their learning experiences made in the course of informal learning activities as a transition from an instructor-based to a teaching-oriented approach, while the learning of the university teachers is focused on contextualisation of their teaching by integrating academic knowledge into the police practice. The article concludes with a brief discussion about the possibilities and limitations of informal learning.
\end{abstract}

Keywords Informal workplace learning · Informal learning conditions · Informal learning activities $\cdot$ Awareness of learning $\cdot$ Police teachers $\cdot$ Police education

David Sjöberg

david.sjoberg@umu.se

1 Unit for Police Education, Umeå University, 90187 Umeå, Sweden

2 Department of Education, Umeå University, 90187 Umeå, Sweden 


\section{Introduction}

The literature shows that professional learning to a large extent emerges through working, and that increasing the understanding of how people learn through work is important (Billett 2011). This article deals with police teachers' informal learning at a police education unit in Sweden. For some years now, police education in Sweden has been undergoing a long-term process of change, which includes increased academisation (Kohlström et al. 2017) and digitalisation (Holmgren et al. 2019). These changes have resulted in increased demands on teachers involved in the training of police officers to broaden their competence and to participate in the ongoing long-term development work. At the studied police education unit, this process of change includes major development efforts focused on teaching content, teaching methods and digital learning resources. In addition, the teaching staff is gradually being extended with teachers of different professional backgrounds. Today, the staff consists of teachers of police subjects, mainly recruited from the local police department, and teachers from academic departments of the university where the unit is located, such as teachers of law, political science and behavioural sciences. As a result of this new constellation of teachers, the studied police education unit can be regarded as a kind of melting pot for different professional experiences and skills which, if integrated, can be an important asset for the teachers' workplace learning. In this study, we explore the conditions for workplace learning, the teachers' engagement in informal learning activities and their learning experiences connected to the learning activities. As shown in the literature, workplace learning is sometimes related to formal educational activities, but more often to informal daily work-related activities such as reflection on job activities, collegial sharing of knowledge (Bednall et al. 2014), performing new tasks and working with and observing others (Crouse et al. 2011). As these examples of activities suggest, informal workplace learning may include both an intentional and an incidental dimension (Jeong et al. 2018).

The body of research on informal workplace learning is extensive and includes several different professional contexts and levels in organisations. However, further research is required in order to capture variations in informal learning in different kinds of working environments (Grant Wofford et al. 2013). Based on these insights, the aim of this study is to contribute knowledge about Swedish police teachers' informal learning. The study draws on the teachers' own accounts of the conditions for learning, learning activities and learning experiences, through data from daily logbook notes and subsequent interviews. The following questions are answered in the study:

1. What conditions can be identified at the police education unit that may constrain or enable the teachers' informal learning?

2. What characterises the teachers' informal learning activities regarding triggers for commitment, engagement in activities and interaction participants?

3. What learning can be identified as emerging from their engagement in informal learning activities?

\section{Police Education}

Basic police education in Sweden consists of a two-and-a-half-year commissioned programme located at five different universities. The police education unit studied 
has a campus-based mode that has been running for almost twenty years and a distance mode introduced a few years ago. The programme content is governed by a programme syllabus designed by the Swedish National Police Authority, but the units have a certain degree of freedom to make their own decisions about the teaching content and design. The unit studied provides teaching in theoretical subjects such as law, political science and behavioural sciences, and police subjects such as weapons and tactics, communication and conflict management, mental and physical preparation, car driving and the use of computer systems and radios. One semester of the program is devoted to field training at a local police department.

The teaching is carried out by police officers employed for specific periods (hereinafter referred to as 'police teachers') and by university teachers. The police teachers usually do not have any formal pedagogical training and can be described as coming from a police instructor tradition. The majority of the university teachers are employed at different university departments and work part time at the unit.

\section{Previous Research on Informal Learning}

Informal workplace learning has been studied in several professional contexts with a focus on different aspects of the informal learning process and different levels in organisations. For example, studies have been carried out in business, industry, healthcare and education contexts (Grant Wofford et al. 2013). However, further research studies in other professional contexts are required in order to capture variations in working environments (Gola 2009; Grant Wofford et al. 2013).

As stated by Jeong et al. (2018), most studies have both an intentional and an incidental perspective, i.e. they focus on both planned informal learning and learning that arises as accidental by-products of the daily work. Furthermore, informal learning activities have been extensively studied, but when it comes to identifying relevant ones, there seems to be great deal of variation in the conclusions arrived at in these studies. Some examples of learning activities described as relevant in the literature are mentoring, peer relationships, temporary job restriction (Cunningham and Hillier 2013), learning with others, self-experimentation and external scanning (Choi and Jacobs 2011). Other studies have reported categories such as 'individual', 'together' 'from others' (Doornbos et al. 2008), 'reflection on daily activities', 'collegial sharing of knowledge' and 'innovative behaviours' (Bednall et al. 2014), 'performing new tasks', 'working with and observing others', 'trial and error', 'reading/researching', 'reflecting on action', 'mentoring', ‘job rotation' and 'networking' (Crouse et al. 2011).

In recent years, increased awareness of the contextual character of informal workplace learning (Manuti et al. 2015) has resulted in many studies considering several levels of analysis, e.g. the individual, group and organisation levels. Jeong et al. (2018) classification of significant factors for informal learning shows that sociodemographic, personal and job characteristics stand out at the individual level, while at the group level, factors such as leadership support, feedback, networking and interpersonal relationships have been identified as important.

It has also been reported that leadership support can facilitate the informal learning process (Pifer et al. 2015), for example by leaders creating space for learning opportunities, serving as coaching mentors, encouraging risk-taking and giving positive 
feedback (Ellinger 2005). In addition, feedback seems to be a crucial resource in the learning process (Holley et al. 2016; Nisbet et al. 2015). For example, Doornbos et al. (2008) show that open communication and collegial feedback can contribute to increased learning activities. Participation in internal and external networks and good relations between employees are other factors that can promote informal learning processes (Doornbos et al. 2008; Schürmann and Beausaert 2016). Holley et al. (2016) claim that strong connections to a more capable colleague are favourable for learning and that good internal relations in terms of clear communication, trust and respect are important prerequisites for workplace learning (Cunningham and Hillier 2013). It has also been reported that social interactions in the workplace are important components supporting employees' informal learning (Boud et al. 2009). At the organisation level, Jeong et al. (2018) find that a supportive workplace culture and environment can facilitate employee participation in learning activities. This seems to apply primarily to new employees, who can thus receive support in their professional development (Neher et al. 2015; Pifer et al. 2015). Jeong et al. (2018) also highlight studies showing the importance of a positive and safe work environment where employees dare to take risks, ask questions and express alternative opinions (Schürmann and Beausaert 2016).

Access to information and communication tools, such as digital internal documents (Cuyvers et al. 2016), the internet and wikis (Milovanović et al. 2012) for sharing knowledge, have been shown to be of value for employees' informal learning. Support from human resource systems is another component facilitating informal learning (Bednall et al. 2014).

In conclusion, this review shows that informal learning encompasses many levels, relationships and activities in an organisation. Informal learning is described as being constantly ongoing and positively or negatively affected by the conditions for learning created within the organisation.

\section{Informal Workplace Learning}

The point of departure of this study is informal workplace learning. In the literature, such learning is described as being situated within a specific work practice and emerging in the activities of everyday work (Boud and Hager 2012; Billett 2011; Boud et al. 2009; Billett 2004). Our study targets teachers at a police education unit and their development as teachers through informal learning, the conditions for informal workplace learning at the unit, the informal learning activities the teachers engage in and the learning experiences derived from such activities. Learning experiences can be described as a concept which overall captures the importance of experiences made in real-life activities (e.g. Dewey 1916/1985; Illeris 2007). In our study, this concept is used with the intention of understanding how teachers' experiences of participating in informal learning activities can contribute to their developing knowledge and skills considered relevant to their teaching assignments.

Defining formal and informal learning can be difficult. In this paper, we argue that the distinction between these concepts can be somewhat fluid and that neither of them is valued as more important than the other for the emergence of knowledge relevant to a particular workplace (c.f. Billett 2004; 2011). However, in order to expand on what we 
mean by informal workplace learning, some sort of distinction between formal and informal learning is needed. Marsick and Volpe (1999) characterise formal learning as 'highly structured, institutionally sponsored and classroom-based learning with an educator or trainer' (p.4). Informal learning, on the other hand, is characterised as being 'predominantly unstructured, experiential, and non-institutionalised' as individuals make sense of their everyday working experiences (p.4; see also Eraut* 2004). A crucial element of informal learning is that it is initiated by the learners themselves, alone or together with others, with the aim of learning about some aspect of the practice (Jeong et al. 2018). Thus, the concept, as used in this study, has a broad meaning of non-formalised learning in the practice that can be driven either by the teachers at the police education unit themselves or occur as incidental and spontaneous forms of learning (c.f. Marsick and Watkins 2001).

Learning conditions are shaped by the people involved in the practice and their general understanding of the workplace. For example, the literature shows that the organisational structure of the workplace as manifested in rules, instructions and guidelines, the culture expressed through motives and values, and material resources such as premises, tools and equipment constitute important parts of a work practice (c.f. Hydle and Hopwood 2019, Schürmann and Beausaert 2016; Boud et al. 2009; Billett 2004). Another prerequisite for informal learning is that there are opportunities to reflect on one's work in the day-to-day practice (Boud 2006). Taken together, learning conditions can be described as part of the working practice and can, to a greater or lesser extent, enable or constrain informal workplace learning (Nyström et al. 2017; c.f. Billett 2004).

Learning constitutes an important part of working and can take place through actions and interactions with colleagues (Boud et al. 2009), for example, when problems and challenges are encountered that need to be addressed in order to be able to move forward (Boud and Hager 2012). Thus, learning at work does not primarily take place in the course of formal activities, but emerges through working with peers in informal ways (Hydle and Hopwood 2019). The literature also shows that informal learning activities are often initiated by triggers (Marsick and Watkins 1997). An intentional start of learning activities involves a trigger, which can arise from a challenge or a knowledge gap (Lave 1988). Mäkitalo (2012) describes the process of learning at work as:

'[...] emerging from challenges in situated activities where professionals need to find ways to be able to 'go on' with their activities and pursue their tasks. [...] learning emerges in situations where gap-bridging, meaning-making and coordination of actions and perspectives are necessary to be able to carry on with ongoing activities' (Mäkitalo 2012, p.61).

An incidental start of the learning process can arise from a so-called 'aha' moment experienced during work (c.f. Bennett 2012) and involves sudden insights generated by events such as conversations during coffee breaks or observations of colleagues in action. However, after an incidental start, the informal learning activities are transformed and become intentional in the same way as the gap-bridging process.

One aspect of informal learning activities is how and with whom the activities are carried out (Jeong et al. 2018). Examples of informal learning activities can be found in the literature, such as performing new tasks, working with and observing others, 
collegial sharing of knowledge, innovative behaviours (Bednall et al. 2014; Crouse et al. 2011) and reflecting on one's own work in productive ways (Boud 2006). Such activities can be carried out on an individual basis or with the support of colleagues or other people (cf. Doornbos et al. 2008).

\section{Method}

In this section, the methodological framework of the study is described with respect to study setting, sampling, data collection methods, procedures and analysis framework.

\section{Study Setting}

Teachers' informal learning at the police education unit constitutes the research object of this study. Their work consists mainly of teaching in classrooms and training environments, and can be divided into three phases, namely planning, implementation and evaluation. Planning is usually carried out through a combination of teachers' individual work, informal dialogues with colleagues and formal team meetings. This combination of informal and formal activities means that the teachers' learning is largely integrated and situated, as it takes place in different constellations and situations. When it comes to the implementation of the teaching, there is usually one teacher who conducts the classroom-based teaching and two or more teachers who are in charge of the practice-oriented lessons. The latter form of teaching enables teachers to immediately observe each other's actions and discuss the implementation and outcome of the exercises. The teaching teams are located in geographically dispersed buildings on campus but have both regular and spontaneous meetings at the police education unit.

\section{Sampling}

The teaching staff at the studied unit consists of some 60 teachers, 40 of whom are police teachers and 20 university teachers. In order to achieve a satisfactory level of the respondents' teaching experience and an acceptable distribution regarding age, gender and teacher category, the following selection criteria were used. First, the respondents should have at least one semester of teaching experience and at least $30 \%$ of their total teaching hours should be done at the unit. Second, the distribution of respondents should, as far as possible, correspond to the actual distribution of age, gender and teacher category at the unit. 45 teachers met the first criterion and the distribution regarding age, gender and teacher category in this group was deemed to be satisfactory. The distribution regarding background variables for teachers was 1 ) teacher category: 15 police teachers and 10 university teachers, 2) gender: 15 men and 10 women, 3) age: 31-62 years and 4) teaching experience: from one to 18 semesters. Written and oral invitations were made to these teachers and 25 of them accepted to participate in the study.

\section{Data Collection Methods}

In view of the nature of the research questions, we decided that several different data collection methods were needed to capture teachers' reflections on their teaching 
experiences, perceptions of the workplace and actions in their daily work. Interviews were chosen because they provide respondents with ample opportunities to reflect on and describe the conditions for informal learning in the workplace in terms of enabling and limiting aspects that the teachers perceive as having an influence on their involvement in various learning activities. Furthermore, the interviews provided an inside perspective on the educational context regarding, for example, work relationships, collaborations, established routines and the respondents' views on the educational mission. Finally, yet importantly, the interviews gave the teachers an opportunity to supplement their digital diary notes with more in-depth comments. The semi-structured interview guide contained the following themes: 1) background questions 2) triggers for engagement in learning activities 3) engagement in activities 4) interacting participants and 5) conditions for informal learning at work. The research questions were operationalised into open interview questions, such as, 'What kind of challenges do you encounter in your daily work as teacher? 'What do you do to overcome these challenges?', 'Who do you turn to when you encounter a problem or need to seek someone's advice in your everyday work?'

In order to strengthen the reliability of the results in terms of the respondents' immediate observations of their daily informal learning activities, the interviews were supplemented with a digital logbook. All respondents were asked to answer the following questions on a daily basis during a four-week period: 1) What knowledge and skills do you need to carry on with your work and why? 2) What do you do to develop the knowledge and skills you need? 3) Who do you turn to for help?

Initially, we had planned to conduct observations of teachers and their learning activities with a view to obtaining additional insights about both the educational context and the teachers' actions and interactions with colleagues in their daily practiceoriented activities. However, due to the programme's schedule structure, lessons and practice sessions are located in many different places, which means that the teachers are absent from the unit for large parts of their working time. As some teachers also expressed a reluctance to be observed, it was decided not to use observations as a data collection method in the study.

The methods selected have some limitations which must be considered. For example, different respondents might have different understandings of the concept of informal learning, which could affect their answers and logbook entries, and they might also have different priorities when it comes to the time they are prepared to spend on the study alongside their regular work commitments. The fact that we decided not to do observations also meant that the practice-oriented perspective was weakened and could only to a certain extent be maintained through the in-depth narratives that emerged in the interviews.

\section{Procedure}

In order to satisfactorily overcome some of these limitations, a covering letter was sent to all teachers at the unit, including descriptions of the aim of the study, selection criteria, our interpretation of key concepts, interview question themes, instructions about the logbook and the ethical aspects of the study. An invitation to participate in the study was then sent via email to all teachers at the unit. The study began with the 25 respondents making their own postings in digital logbooks. The number of individual 
postings varied from 15 to 90 , ranging from brief notes to long and detailed comments. One month later, 23 of the 25 respondents were interviewed (the remaining two were not available due to absence). The interviews, which lasted between 55 and $90 \mathrm{~min}$, were conducted at the university and recorded using a sound recorder.

\section{Data Analysis}

After transcription and overall reading of the digital logbooks and interviews, the systematic entries made by the respondents in the digital logbooks and their narratives in the interviews were categorised and coded in several steps. Initially, each note and statement was marked with a provisional code. In a second step, the aggregated analysis revealed several codes with a similar content, many of which could be merged, which resulted in a reduction of the material. The analysis in this phase continued until saturation had been achieved, i.e., until no more new categories could be identified (Kvale and Brinkmann 2009). In order to structure the material, the next phase consisted of sorting the identified categories under the themes 'conditions for informal learning', 'learning activities' and 'teachers' learning experiences'. Finally, concepts related to informal workplace learning were used as a means to deepen the understanding of the material.

The identified categories sorted under the first theme, 'conditions for informal learning', came from the respondents' narratives in the interviews. In this kind of approach, respondents' narratives are used to capture how they understand the world (Boud et al. 2009). The analysis was focused on how the conditions at the police education unit either enabled or constrained the teachers' informal workplace learning. Understanding these conditions and how they shape the teachers' opportunities to learn at work are important for understanding more precisely what and how they learn (Billett 2004). The categories identified as belonging to the second theme, 'informal learning activities', derived from both interviews and logbooks. In the analysis, attention was paid to what characterises the respondents' informal learning activities regarding triggers for commitment, engagement in activities and interaction participants. The teachers' entries in the digital logbooks were also analysed quantitatively. The number of postings for each identified category was counted and summarised. Finally, the learning experience concept was used as a convenient way to capture and discuss the teachers' perceptions of what they have learnt at work.

\section{Findings and Analysis}

This section presents the study's findings, structured according to the following themes: 1) conditions for informal learning, 2) informal learning activities and 3) teachers' learning experiences.

\section{Enabling and Constraining Conditions for Informal Learning}

In the teachers' narratives of their workplace, three categories emerge regarding the conditions for informal learning which were coded as 'culture', 'structure' and 'material resources'. These are shown to have an important impact on the teachers' informal 
learning and the teachers provide several examples of their enabling and constraining effects on their learning at work.

The workplace culture is generally perceived as conducive to learning and the teachers describe the positive energy at the workplace as a general sense of development and progression among the staff. For example, some university teachers consider the police education unit a more development-oriented workplace than their home department.

'There is a great interest in developing teaching here, while in many other places in the university there is a considerably greater focus on research, and educational initiatives have to some extent stalled' (University teacher).

The interviews provide a picture of the police education unit as a workplace where teachers talk to each other and feel comfortable discussing teaching matters with each other. Further, judging by the teachers' narratives, these types of contacts do not seem to be restricted only to the colleagues in their own teaching team. Instead, the mix of teachers with different experiences and competences, both from different university departments and from the police service, provide the teachers with greater access to sources of new learning. This culture seems to be influenced by the current process of change at the police education unit. For example, the teachers state that the work towards developing a distance-based programme mode and the new teaching methods needed to cope with the increased number of students admitted to the program have made it necessary for them to increase their contacts outside their own teaching teams. Consequently, they feel more comfortable than before about approaching other teachers, as described by a police teacher: 'Before, contacts between teaching teams used to be limited. However, the work towards developing the distance-based mode has led to changes in this respect'. This quote exemplifies how the development work has helped to blur the boundaries between the teaching teams in a positive way. Another enabling aspect emerging in the findings is that the management is perceived as being supportive of informal learning and encourage the sharing of experiences and good teaching examples e.g. through presentations on staff days, at workplace meetings or in the everyday work practice.

However, a few constraining aspects involving the culture also emerged in the narratives. For example, teachers point out differences between colleagues and between teams regarding their openness and willingness to share knowledge. These circumstances seem to affect the teachers' choice of contacts with colleagues when they need help or wish to discuss a teaching matter. For similar reasons, teachers may be hesitant to contact certain teams for discussions or collaborations.

Two aspects of the structure of the workplace and its impact on informal learning appear in the narratives, namely the physical location of the programme and the time allocated for collegial collaboration. The interviews show that the physical location of the workplace is considered important for enabling informal learning. But the police education unit is located in different buildings and city districts, which means that the teaching teams do not meet regularly. The teachers regard this as a constraining factor making cross-disciplinary collaboration and informal learning more difficult, and many teachers expressed a hope that the projected new Police Education Building will contribute to extended collaboration throughout the programme. Furthermore, the 
interviews show that, in order to enable informal learning, time must be allocated in work schedules for informal meetings with colleagues and reflections on one's own teaching practice. However, this entails that teachers be present at work even when they are not teaching.

'We want students to reflect on and discuss their experiences, but this is also important for us teachers [...] even though time is scarce due to busy teaching schedules' (University teacher).

This quote exemplifies that overly packed work schedules constrain the teachers' opportunities to engage in informal learning activities with incidental starts, due to the lack of break time in the work schedules (see Boud 2006). Another constraining circumstance involving the structure pointed out in the interviews is the different ratios between annual teaching hours and annual working hours for different kinds of teaching. For example, a teacher teaching a practical subject may be assigned two working hours per teaching hour while someone who is teaching a theoretical subject is usually assigned four working hours per teaching hour. Thus, many of those who teach practical subjects spend more of their annual working time teaching and have less time for planning and developing their teaching than those who teach theoretical subjects, which means that they have fewer opportunities for learning with peers in informal ways.

The interviews also show that the material resources (tools and equipment) are important elements of the conditions for workplace learning. As presented in the next section, some needs are dealt with face-to-face. However, there are other needs where e-mail, telephone or apps constitute important tools for informal learning. The developed IT structure at the unit and how it affects the role of the teacher is often highlighted in the narratives. An IT structure comprising cameras in the practice environments, opportunities to both record and stream teaching sessions, smartboards, simulators and software solutions for various aspects of teaching requires that teachers have technology-specific knowledge. This means that such knowledge becomes central to their work and can be seen as either constraining or enabling, depending on the teachers' individual level of digital knowledge. Further, knowing how to use different IT tools, such as computers, software, video equipment, links to support, LMS and online schedules, is described by the teachers both as a means for learning and a learning object in itself. Thus, knowing how to use these material resources enables the teachers to focus more on teaching matters.

\section{Teachers' Informal Learning Activities}

The results that concern teachers' informal learning activities are based on logbook notes and interviews. The results are presented under the headings 'Triggers for teachers' involvement in learning activities', 'Teachers' learning activities' and 'Interaction participants'.

\section{Triggers for Teachers' Involvement in Learning Activities}

In the teachers' logbook notes and the interviews, the following five categories of knowledge areas can be identified as triggers for their involvement in learning 
activities: pedagogy, technology and design, subject, administration and organisation, and programme goals, assignments and approaches.

Half of the activities in the logbooks, 150 out of 301, are initiated by triggers involving pedagogical issues, where the teachers feel they need more knowledge about teaching-oriented matters such as planning, implementation and monitoring. The pedagogical issues can be divided into those concerning general methodology, which are primarily seen as important by newly recruited police teachers, and pedagogical questions related to the ongoing digitalisation, which are brought up by most of the teachers. The majority of these triggers result in intentionally-driven learning activities where teachers often seek out an experienced or specifically knowledgeable colleague for face-to-face dialogues. A small number of pedagogically oriented triggers occur as aha-moments in connection with teachers' observation of colleagues' teaching or discussions during breaks. Subsequent learning activities follow a pattern similar to that of the intentionally driven ones.

The interviews also show that pedagogy is the most central category, including a variety of both intentional and sometimes incidental triggers. Common examples of knowledge gaps and intentional learning are teachers' attempts to implement new pedagogical methods, to identify the core of their subject or to develop their teaching approach. An example of a specific trigger is requests from relatively newly recruited teachers for practical teaching tips, e.g. on how to manage a student group during a training exercise or different ways of giving feedback. One police teacher explains their need for learning in the following way: 'I need to learn new teaching methods that I haven't had the opportunity to learn before, as I've been stuck in an instructor role in the police organisation'. These specific triggers usually arise from informal conversations with or observations of other teachers. Furthermore, this category also includes structural aspects of teaching, such as knowledge of the constructive alignment between learning goals, course content and examinations. A specific trigger for the university teachers, who lack experience of police practice, is their wish to adapt their teaching to a police context by learning from the police teachers with their specific police experience and professional skills.

'Since I teach on a police education programme and have no police experience, I sometimes need input from police teachers on how to design an exercise and how to place it in a specific context so that it is more adapted to policing. Sometimes I need feedback on my teaching approach to find out whether it is completely irrelevant or something that seems reasonably okay' (University teacher).

About one-fifth, or 18\%, of all learning activities recorded in the logbooks are initiated by triggers involving digital technologies. Such triggers usually arise in the planning of teaching and concern either the function of digital tools and how they can be used as support in teaching, or how police equipment works and is used in the police service and in education. All such triggers lead to intentionally driven learning activities where teachers contact specifically knowledgeable colleagues via mail, telephone or face-to-face with a view to deepening their own knowledge. These results are confirmed in the interviews, which also show that this category includes triggers relating to hardware, such as computers and cameras, and ICT-questions about the management of course platforms and digitalisation of course content. Such triggers are described as mostly intentional, as problems of this kind are usually encountered in the daily teaching practice. 
The third trigger category, subject, constitutes $14 \%$ of the activities and concerns the teachers' need to deepen and broaden their subject knowledge. These triggers are largely linked to teachers' efforts to improve their teaching by adding a police perspective or integrating their own subject with other subjects. This type of trigger occurs to a greater extent among teachers in subject-integrated work teams, compared to subject-specific work teams. For many university teachers, it is often a matter of developing knowledge of police methods and routines and the legal basis for police work. Other teachers, both university and police teachers, often seek additional knowledge about health care and communication skills. These types of triggers are intentionally driven and usually lead to face-to-face contacts with colleagues. The interviews show that this type of trigger includes overarching questions such as what the core content of a subject is, as well as more specific matters, such as experiences of various kinds of situations in police work and knowledge of subject-specific teaching methods. One police teacher describes their need for knowledge in the following way: 'What I mostly think about is whether I can do a particular thing in a certain way. And then I discuss it with my teaching team'. The subject theme also includes more lesson-specific triggers, such as ones relating to fine-tuning details in a lesson plan, adapting teaching levels to students' prior knowledge and suggestions on effective ways of acting professionally in different situations. One police teacher states that "there are techniques I have not used myself as a police officer but I have to teach them here on the course".

The fourth category, administration and organisation, representing $13 \%$ of the logbook entries, is about teachers' need to know more about staffing plans, teaching schedules and educational guidelines and policies. The interviews show that this category includes administrative questions such as how to report grades on the course platform or questions about schedules. Other questions may concern access to specific locations in police education buildings or equipment related to a specific course content.

Finally, the last category, program goals, assignments and approaches, representing $5 \%$ of the logbook entries, concerns intentional triggers and relate to questions of a general nature that can be divided into two subcategories, namely general questions about the programme goals and structure, including connections between the educational content and the National Police Authority's mission, content links between courses and questions about how to adapt the course content to suit the distance mode.

\section{Teachers' Ways of Acting in Informal Learning Activities}

In the teachers' logbook entries, four subcategories emerge in this theme, which concern the tools and methods teachers apply to bridge their knowledge gaps. These categories are confirmed in the interviews where the teachers also provide detailed descriptions of what happens in these learning activities. The categories identified are face-to-face, e-mail, telephone and individual work. Face-to-face usually refers to intentional contacts within the teaching teams and sometimes with specifically knowledgeable colleagues. Such contacts are the most usual ones when it comes to matters involving subject-oriented, pedagogical and programme goals, assignments and approaches. In some cases, triggers relating to the first two categories also lead to continued dialogues via tools such as e-mail, in order to make further clarifications or obtain additional advice. Face-to-face contacts usually take place in teachers' offices or during breaks in common areas. 
'I turn to my colleagues when I have discovered something in my teaching that needs to be corrected or when I have made some changes that I would like to have confirmed' (Police teacher).

When it comes to triggers related to 'technology and design' and 'administration and organisation', teachers usually use $e$-mail. In the former case, they usually turn to specifically knowledgeable colleagues for advice on, for example, the use of digital tools and course platforms. The more knowledgeable colleagues then often provide support by referring to pedagogical digital solutions they have designed and tested in their own teaching. The latter case involves necessary and concise information such as staffing plans, teaching schedules etc. which the teachers need for the planning of their teaching.

The teachers use the telephone mainly for triggers related to 'technology and design' and 'administration and organisation' while instant messaging and group applications are usually used when teachers need quick information about teaching scheduled for the following day or the coming week, for example regarding the choice of technology and equipment, student group divisions and division of responsibilities among the teachers.

A majority of the teachers, especially those with less teaching experience, seem to make extensive use of the abovementioned tools and methods in their learning activities. However, some teachers with longer experience state that they often first try to deal with emerging triggers on their own, for example by seeking information in internal training documents and on government websites, and when it comes to practical matters, by adopting a trial-and-error approach to find possible solutions.

Spontaneous contacts with other colleagues also constitute part of the teachers' learning activities, but they are less common than the intentionally driven ones. These activities are described as 'corridor' or 'coffee-room' dialogues, which can act as triggers of an incidental nature. For example, when a teacher tells other teachers about his or her experience of a specific teaching method, this often leads to follow-up discussions where colleagues ask for more information.

\section{Motives and Resources for Informal Learning}

The people teachers contact and interact with in order to bridge their knowledge gaps can be divided into five subcategories: 1) Colleagues in the teaching team, 2) Internal key persons at work, 3) Internal formal experts, 4) Management personnel and 5) External contacts/experts. Table 1 shows the distribution of the teachers' contacts.

As shown in Table 1, the teachers primarily turn to colleagues in their own teaching team. This approach is most common in subject-specific teaching teams where colleagues are usually located in the same building, have similar subject knowledge and teaching experiences and are jointly responsible for certain parts of the teaching. Through such contacts, the teachers are given the opportunity to receive support in their planning of their own and shared lessons or to discuss how they can design entire courses together. The findings also show that some of the teachers in these teams only rarely turn to colleagues outside their own team.

Many teachers also turn to colleagues they perceive as internal key persons at work. These key people are often described as having extensive experience of teaching or the police profession, and are perceived as specifically knowledgeable in their subject area or in teaching methods. For example, many turn to teachers of law for advice on legal matters 
relating to their own subject or course. Another example is police teachers seeking guidance and support in educational matters from university colleagues at the Department of Education. One police teacher describes their learning as follows: 'Most of us have no teacher training, but fortunately we have several qualified teachers in our corridor. I learn both by observing them and talking to them about teaching matters'. However, a key person can also be a teacher possessing cutting-edge skills in, for example, digital technology, and who is seen as a prime mover in the development of that field.

Other identified participants are less often involved in the learning activities. External contacts / experts are persons outside the unit, such as teachers, leaders and experts at other police education units, the local police department or other authorities. Such contacts usually concern existing collaborations or updates regarding police digital systems, tactics and forensics. The management category consists of programme management staff to whom the teachers turn, for example, for confirmation regarding their interpretations of programme goals or to discuss suggested changes to a course. Finally, internal formal experts are staff who have explicit support positions at the unit. This subcategory includes administrative staff and caretakers responsible for training materials and technical support. However, teachers' contacts with these internal formal experts make up only a small proportion of all contacts.

\section{Teachers' Learning Experiences}

When the teachers reflect on their learning experiences, 'pedagogically-oriented' teaching knowledge emerged as important to them. Such knowledge concerns planning, implementation, assessment and administration of teaching, for example the teachers' approach to teaching, teaching performance and use of specific methods and tools. One police teacher describes their informal learning at work as a gradual transformation from instructor to teacher as they develop new pedagogical skills, for example ways to manage a group of students during a training exercise, give feedback, maintain the flow of an activity and get students more involved.

'[...] I often think about how I teach and how I behave in the classroom. Do I see everyone and give them feedback? What do I say and what do they hear? And when it comes to pedagogical questions about exercises, do I provide them with the right tools, am I doing the right things or should I make some changes?' (Police teacher).

Table 1 Distribution of teachers' contacts. Based on the logbook analysis. $N=361$ listed contacts, of which 60 are follow-up contacts concerning a previously discussed matter

Categories of persons contacted

\begin{tabular}{lllll}
\hline $\begin{array}{l}\text { Colleagues in the } \\
\text { teaching team }\end{array}$ & $\begin{array}{l}\text { Internal key } \\
\text { persons at work }\end{array}$ & $\begin{array}{l}\text { Internal } \\
\text { formal experts }\end{array}$ & $\begin{array}{l}\text { Management } \\
\text { personnel }\end{array}$ & $\begin{array}{l}\text { External } \\
\text { contacts /experts }\end{array}$ \\
\hline $43 \%$ & $32 \%$ & $3 \%$ & $10 \%$ & $13 \%$ \\
\hline
\end{tabular}


This quote illustrates how the teachers experienced their own learning and development which influence their daily work, and points to an understanding of the importance of a solid pedagogical approach to teaching. Further, many teachers also state that the collaborative collegial work has resulted in their 'pedagogical toolbox' having become larger and that they can vary their teaching methods. Also, an increased understanding of the police context is apparent in the university teachers' narratives about what they have learnt at the police education unit. This knowledge is used as a way of contextualising the specific subject they teach and to situate and adapt it to better suit the police students' needs.

The teachers' narratives also show that they have learnt that knowledge of where and when activities occur are important for working at the police education unit. For example, teachers describe that they need to have knowledge about work procedures, such as examination, grading on the course platform and reporting the grades in the university's digital report system. Another example of this form of knowledge is given by a teacher who describes how their knowledge of the links between their course and other courses has developed over time and influenced their teaching.

Further, it appears from the teachers' narratives that they have learned who to turn to for support and advice and how this is of importance for their own problem solving and development. Such knowledge includes both knowing of formal roles in the unit, e.g. support and administrative staff, as well as of informal ones, such as key persons who are knowledgeable in a specific field such as law, pedagogy or digital technology. One police teacher expressed this knowledge in the following way: 'I try to think of someone who knows more about a particular issue than me. And then I approach that person'. This quote illustrates the importance of knowing who to approach about specific work-related matters. The teachers' narratives show that they are aware that they learn over time who they should contact and that this knowledge is highly relevant for teachers at a police education unit. Teachers descriptions of knowing 'who' also points to the culture of the work place, where the general feeling is that they now feel more comfortable about approaching more knowledgeable colleagues.

\section{Discussion and Conclusions}

In line with previous studies (c.f. Jeong et al. 2018; Schürmann and Beausaert 2016), this study indicates that the culture and the structure of the workplace and the material resources constitute important conditions for the teachers' engagement in learning activities. Examples of enabling conditions are a largely integrated organisational structure, a pronounced interest among the teachers to contribute to the development of the teaching (c.f. Doornbos et al. 2008), a mix of different experiences and skills among teachers and a well-developed digital communication structure (c.f. Cuyvers et al. 2016). Not least, the integrated organisational structure, which is based on subjectintegrated work teams and interdisciplinary cooperation between these teams, seems to contribute to an effort among teachers to broaden their focus from specialised subject teaching to how to jointly achieve the goals of a complex programme syllabus. Together, these conditions seem to constitute an important foundation that encourages teachers to turn to colleagues and other work teams for support and advice on how to address the challenges they face in their daily work (c.f. Boud and Hager 2012; Crouse 
et al. 2011). At the same time, the results show that there are teachers and work teams who do not participate in informal learning activities outside their own work team, which from a learning and organisational perspective can be seen as a constraining aspect. Our results indicate that the composition of the work teams (subject-specific or subject-integrated) and the team culture may be factors contributing to certain work teams tending to isolate themselves.

When it comes to the teachers' informal learning activities, three themes can be highlighted. First, the study shows that the 'how' question, i.e. pedagogical questions about planning, implementation and evaluation of teaching, constitutes the most central trigger for the teachers' learning activities. These knowledge questions in play range from general design and planning issues to specific issues relating to, for example, the use of teaching-oriented technologies and police equipment. The teachers' background as either academics or police officers greatly influences the knowledge and skills they seek in their learning activities. For example, police teachers with limited teaching experience are primarily involved in gap-bridging activities (c.f. Neher et al. 2015), where they strive to learn more about pedagogical and digital technology matters. On the other hand, the gap-bridging activities of the academics are dominated by the whatquestion, i.e. questions oriented to the professional practice such as police routines, legal support and equipment. While these results are not surprising, they show that integrated subjects and a mix of employees with varied professional experiences and skills constitute important conditions for the development of learning environments in vocational programmes.

Second, the study shows that the teachers' informal learning activities are predominantly of an intentional nature (c.f. Jeong et al. 2018), i.e. they are based on, for example, everyday pedagogical problems, a lack of knowledge of a subject area or efforts to improve a particular aspect of their teaching. Furthermore, their contacts with other colleagues often take place face-to-face. Their choice of such contacts is most evident when it comes to teaching-oriented issues that require extensive dialogues and knowledge sharing (c.f. Bednall et al. 2014). Thus, the results indicate that these teachers meet the challenges posed by the current educational changes in the unit by gradually developing a learning environment based on their knowledge of colleagues' skills, their trust in each other (c.f. Cunningham and Hillier 2013) and a feeling of responsibility to contribute to the development of the programme.

Third, it appears that teachers primarily turn to colleagues in their own team for general advice. When they have needs requiring specific knowledge, they turn to more knowledgeable colleagues with special skills in, for example, technology-rich teaching, police equipment or law, who are thus regarded as valuable informal key persons at work (c.f. Holley et al. 2016). The results indicate that the value of such key persons in the programme's learning environment cannot be overestimated. Thanks to their specific and in-depth knowledge and skills, other teachers, by engaging with them in informal learning activities, are given access to in-depth knowledge and skills enabling them to continuously develop their teaching skills.

Furthermore, when it comes to the teachers' learning experiences associated with their involvement in informal learning activities, three fields of knowledge can be identified: 1) implementation of teaching, 2) the frameworks of the teaching practice and 3 ) their colleagues' experiences and competences. The first field concerns pedagogically oriented knowledge which, according to many of the teachers, in particular 
the police teachers, they continuously develop by engaging in informal learning activities. The second concerns knowledge of rules, guidelines and approaches that, above all, newly recruited teachers need to learn in order to plan and implement teaching. Therefore, the recruitment of new teachers appears to be a driving force in the informal learning activities, as their quest to understand the teaching practice and develop their skills contribute to experienced teachers also being involved in reflection on established approaches. The third field concerns the teachers' knowledge about their colleagues and their experiences and skills, which gradually develops through a longterm commitment to informal learning activities.

However, the main conclusions of this study should be viewed in the light of the changes that the studied police education unit is currently undergoing (Holmgren et al. 2019; Kohlström et al. 2017). The contribution of this study to the field of informal workplace learning is that extensive changes involving academisation, digitalisation and recruitment pose daily challenges for the teachers at work which, over time, are important driving forces in the creation of a learning environment where teachers are engaged to a great extent in informal learning activities.

Depending on the complexity of the daily challenges, teacher teams, experienced teachers and key people are involved in learning activities in varying degrees where the teachers' different professional experiences constitute important sources of knowledge that can help them to develop the knowledge and skills they need as teachers.

In the development of this informal learning environment, the teachers' practiceoriented knowledge of colleagues' competences and support resources are an important basis for being able to deal with changes that affect the day-to-day work. The two teacher categories have different knowledge and skills needs, from the police teachers' ambition to proceed from an instructor-based to a learning-oriented approach, to the university teachers' need to contextualise their academically-oriented teaching in the police practice. Thus, it seems that this needs-driven exchange of knowledge between colleagues creates a win-win situation for the teachers involved and also contributes to strengthening the collective knowledge and the teachers' joint readiness to respond to new education changes. Taken together, this study shows that while externally decided education changes can create different kinds of challenges for teachers, these challenges can to a large extent be successfully overcome if the teachers' collective experiences and competences are utilised and if the cultural and structural conditions enable informal learning. The melting pot metaphor in the introduction thus has to some extent its justification in this study.

Despite the fact that our findings demonstrate the teachers' positive perceptions of, and commitment to, informal learning activities, there might be risks involved in relying exclusively on this form of workplace learning. We believe that overly defined and formal teacher coalitions, such as extensive work in subject-specific teams with authoritarian leaders, risk having a stagnating effect over time that will limit teachers' ability to critically reflect on their practice and relate their own work to the overall educational mission. Furthermore, this may cause limitations for education programmes when it comes to maintaining transparency regarding overall goals, implementation of teaching and development needs. Given these risks, we believe that regular formal meetings and continuous educational efforts, including shared reflections on the aforementioned aspects, are important in order to both problematise and support the learning that takes place through informal learning activities at work. 
The theoretical framework of this study, which is based on previously developed theoretical concepts (see Jeong et al. 2018; Marsick and Watkins 1997; Mäkitalo 2012; Nyström et al. 2017), can be seen as an attempt to connect several aspects of informal workplace learning. In our opinion, this approach contributes to an increased understanding of how the different parts interact and how they are mutually interconnected, for example, how cultural and structural conditions can enable or constrain the teacher's involvement in informal learning activities and how knowledge of teachers' learning activities and their learning experiences can contribute to a better understanding of how these activities may be supported in the workplace.

Two data collection methods, interviews and digital logbooks, were used in this study. The two methods were complementary by their different time horizons, focus and room for respondents' descriptions, and together they helped to make the data material more precise and in-depth. However, the large variations in the scope and precision of the logbook entries result in some uncertainty as to the extent to which the results are affected by the teachers' different understanding of the concept of informal learning and to what extent they prioritised their logbook writing. We also consider it very likely that observations of the teachers in their daily work would have contributed to even more in-depth insights into their informal learning as teachers.

Finally, the results of this study give rise to a number of questions that we believe are important to address in future research, for example vocational teachers' view of informal learning as a foundation for professional development and for the development of their teaching. Another way to further advance the knowledge of these teachers' informal learning might be deeper mappings of teachers' interaction patterns, for example through social network analyses.

Funding Open access funding provided by Umea University.

Open Access This article is licensed under a Creative Commons Attribution 4.0 International License, which permits use, sharing, adaptation, distribution and reproduction in any medium or format, as long as you give appropriate credit to the original author(s) and the source, provide a link to the Creative Commons licence, and indicate if changes were made. The images or other third party material in this article are included in the article's Creative Commons licence, unless indicated otherwise in a credit line to the material. If material is not included in the article's Creative Commons licence and your intended use is not permitted by statutory regulation or exceeds the permitted use, you will need to obtain permission directly from the copyright holder. To view a copy of this licence, visit http://creativecommons.org/licenses/by/4.0/.

\section{References}

Bednall, T. C., Sanders, K., \& Runhaar, P. (2014). Stimulating informal learning activities through perceptions of performance appraisal quality and human resource management system strength: A two-wave study. Academy of Management Learning and Education, 13(1), 45-61.

Bennett, E, E. (2012). A four-part model of informal learning: Extending Schugurensky's conceptual model. Proceedings of the Adult Education Research Conference, Saratoga Springs, NY. Retrieved from http:// newprairiepress.org/aerc/2012/papers/3.

Billett, S. (2004). Workplace participatory practices: Conceptualising workplaces as learning environments. Journal of Workplace Learning, 16(6), 312-324. 
Billett, S. (2011). Learning in the circumstances of work: The didactics of practice. Education et didactique, 5(5.2), 125-146.

Boud, D. (2006). Creating the space for reflection at work. In D. Boud, P. Cressey, \& P. Docherty (Eds.), Productive reflection at work (pp. 158-169). London: Routledge.

Boud, D., \& Hager, P. (2012). Re-thinking continuing professional development through changing metaphors and location in professional practices. Studies in Continuing Education, 34(1), 17-30.

Boud, D., Rooney, D., \& Solomon, N. (2009). Talking up learning at work: Cautionary tales in co-opting everyday learning. International Journal of Lifelong Education, 28(3), 323-334.

Choi, W., \& Jacobs, R. L. (2011). Influences of formal learning, personal learning orientation, and supportive learning environment on informal learning. Human Resource Development Quarterly, 22(3), 239-257.

Crouse, P., Doyle, W., \& Young, J. D. (2011). Workplace learning strategies, barriers, facilitators and outcomes: A qualitative study among human resource management practitioners. Human Resource Development International, 14(1), 39-55.

Cunningham, J., \& Hillier, E. (2013). Informal learning in the workplace: Key activities and processes. Education+ Training, 55(1), 37-51.

Cuyvers, K., Donche, V., \& Van den Bossche, P. (2016). Learning beyond graduation: Exploring newly qualified specialists' entrance into daily practice from a learning perspective. Advances in Health Sciences Education, 21(2), 439-453.

Dewey, J. (1916/1985). Democracy and education: An introduction to the philosophy of education. New York, NY: Macmillan.

Doornbos, A. J., Simons, R. J., \& Denessen, E. (2008). Relations between characteristics of workplace practices and types of informal work-related learning: A survey study among Dutch police. Human Resource Development Quarterly, 19(2), 129-151.

Ellinger, A. D. (2005). Contextual factors influencing informal learning in a workplace setting: The case of "reinventing itself company". Human Resource Development Quarterly, 16(3), 389-415.

Eraut*, M. (2004). Informal learning in the workplace. Studies in Continuing Education, 26(2), 247-273.

Gola, G. (2009). Informal learning of social workers: A method of narrative inquiry. Journal of Workplace Learning, 21(4), 334-346.

Grant Wofford, M., Ellinger, A. D., \& Watkins, K. E. (2013). Learning on the fly: Exploring the informal learning process of aviation instructors. Journal of Workplace Learning, 25(2), 79-97.

Holley, D., Santos, P., Cook, J., \& Kerr, M. (2016). "Cascades, torrents and drowning” in information: Seeking help in the contemporary general practitioner practice in the UK. Interactive Learning Environments, 24(5), 954-967.

Holmgren, R., Holmgren, T., \& Sjöberg, D. (2019). Teaching and learning in redesigned digitalized learning environments: A longitudinal study at the police education in Sweden. In 12th annual International Conference of Education, Research and Innovation, 11-13 November, 2019, Seville, Spain (1976-1985). Spain: IATED Academy.

Hydle, K, M., \& Hopwood, N. (2019). Practices and knowing in transnational knowledge-intensive service provision. Human Relations, 72(12), 1948-1972.

Illeris, K. (2007). What do we actually mean by experiential learning? Human Resource Development Review, $6(1), 84-95$.

Jeong, S., Han, S. J., Lee, J., Sunalai, S., \& Yoon, S. W. (2018). Integrative literature review on informal learning: Antecedents, conceptualizations, and future directions. Human Resource Development Review, $17(2), 128-152$.

Kohlström, K., Rantatalo, O., Karp, S., \& Padyab, M. (2017). Policy ideals for a reformed education. How police students value new and enduring content in a time of change. Journal of Workplace Learning, $29(7 / 8), 524-536$.

Kvale, S., \& Brinkmann, S-E. (2009). Den kvalitativa forskningsintervjun. Lund: Studentlitteratur.

Lave, J. (1988). Cognition in practice: Mind, mathematics and culture in everyday life. New York: Cambridge University Press.

Mäkitalo, Å. (2012). Professional learning and the materiality of social practice. Journal of Education and Work, 25(1), 59-78.

Manuti, A., Pastore, S., Scardigno, A. F., Giancaspro, M. L., \& Morciano, D. (2015). Formal and informal learning in the workplace: A research review. International Journal of Training and Development, 19(1), $1-17$.

Marsick, V. J., \& Volpe, M. (1999). The nature and need for informal learning. Advances in Developing Human Resources, 1(3), 1-9. 
Marsick, V, J., \& Watkins, K, E. (1997). Lessons from informal and incidental learning. In: J. Burgoyne \& M. Reynolds (Eds.), Management learning: Integrating perspectives in theory and practice (pp.295-311). Newbury Park, CA: Sage.

Marsick, V. J., \& Watkins, K. E. (2001). Informal and incidental learning. New directions for adult and continuing education, 2001(89), 25-34.

Milovanović, M., Minović, M., Štavljanin, V., Savković, M., \& Starčević, D. (2012). Wiki as a corporate learning tool: Case study for software development company. Behaviour and Information Technology, 31(8), 767-777.

Neher, M, S., Ståhl, C., \& Nilsen, P. (2015). Learning opportunities in rheumatology practice: a qualitative study. Journal of Workplace Learning, 27(4), 282-29.

Nisbet, G., Dunn, S., \& Lincoln, M. (2015). Interprofessional team meetings: Opportunities for informal interprofessional learning. Journal of Interprofessional Care, 29(5), 426-432.

Nyström, S., Dahlberg, J., Edelbring, S., Hult, H., \& Abrandt Dahlgren, M. (2017). Continuing professional development: Pedagogical practices of interprofessional simulation in health care. Studies in Continuing Education, 39(3), 303-319.

Pifer, M. J., Baker, V. L., \& Lunsford, L. G. (2015). Academic departments as networks of informal learning: Faculty development at liberal arts colleges. International Journal for Academic Development, 20(2), $178-192$.

Schürmann, E., \& Beausaert, S. (2016). What are drivers for informal learning? European Journal of Training and Development, 40(3), 130-154.

Publisher's Note Springer Nature remains neutral with regard to jurisdictional claims in published maps and institutional affiliations. 